A Variable Grid FDM Technique for Treating Solid-Liquid and Solid-Air Boundaries in Wave Propagation Modeling of Elastic Waves. Task 2, Computer Program

A. Pitarka

March 15, 2012 
This document was prepared as an account of work sponsored by an agency of the United States government. Neither the United States government nor Lawrence Livermore National Security, LLC, nor any of their employees makes any warranty, expressed or implied, or assumes any legal liability or responsibility for the accuracy, completeness, or usefulness of any information, apparatus, product, or process disclosed, or represents that its use would not infringe privately owned rights. Reference herein to any specific commercial product, process, or service by trade name, trademark, manufacturer, or otherwise does not necessarily constitute or imply its endorsement, recommendation, or favoring by the United States government or Lawrence Livermore National Security, LLC. The views and opinions of authors expressed herein do not necessarily state or reflect those of the United States government or Lawrence Livermore National Security, LLC, and shall not be used for advertising or product endorsement purposes.

This work performed under the auspices of the U.S. Department of Energy by Lawrence Livermore National Laboratory under Contract DE-AC52-07NA27344. 


\section{A Variable Grid FDM Technique for Treating Solid-Liquid and Solid-Air Boundaries in Wave Propagation Modeling of Elastic Waves. Task 2, Computer Program}

In Task1 we explained the layout of the staggered grid adopted in the UL0_2.4 a finitedifference computer program developed by Pitarka $(1996,1999)$. The objective of the second task is to modify the UL0_2.4 program in order to extend its application to computing elastic wave propagation in heterogeneous structures with irregular surface topography and solid-liquid boundaries. The new program UL0_2.4W preserves the structure and variable-grid finite-difference technique used in the original computer program. The list of computer programs for running the FD code, and programs for postprocessing the output data is given in the Appendix.

We modified several subroutines of the UL0_2.4, including the subroutines for modeling boundary conditions, and particle velocity and stress at or near the boundaries. UL0_2.4W can run on multi core machines when compiled with OpenMP.

\section{Boundary Conditions}

As explained in the URS report of last year, the computer program is based on a staggered grid finite-difference scheme in which the normal-stress components are calculated in the center of the finite-difference unit cell, while the density, particle velocity and shear-stress components are calculated on the sides and edges of the cell. The boundary between two different materials is assumed to lie on the sides of adjacent unit cells. This grid arrangement enables the application of a new simple boundary condition scheme proposed by Takenaka et al. (2009) that implicitly satisfies the continuity of the shear stress and forces normal stress to be zero at the solid-liquid and solid-air boundaries.

\section{Simulation of Wave Propagation for Slab Heterogeneous Model With Water layer}

Here we demonstrate the capability of the new program for modeling solid-liquid and liquid-air boundary conditions by computing seismic waves for a double-couple point source using the velocity model of a subducting plate. The velocity model includes the oceanic water layer. We used a double coupe point source with an arbitrary thrust mechanism located $9 \mathrm{~km}$ below the oceanic water layer.

Figure 1 shows an E-W cross-section of the 3D velocity model. We examined the velocity waveforms at a linear array of receivers located at the ocean floor (see Figure 1). In order to separate the effects of the water layer on wave propagation at stations on the ocean floor we compared velocity seismograms calculated with two different velocity models. The first model contains the air-water boundary, and the second model has a water layer with infinite thickness (the air-water boundary is replaced by an absorbing boundary). Figure 2 shows the corresponding vertical component seismograms band-pass filtered at $0.01-1.5 \mathrm{~Hz}$. In our simulations we used a regular grid with a $100 \mathrm{~m}$ grid 
spacing. The waveform modeling is accurate up to $1.5 \mathrm{~Hz}$. Wave reverberations within the ocean layer dominate the later phases of the calculated wavefield at the ocean bottom receivers (rec\# 2-20). A dramatic reduction of the ground motion amplitude is observed at receivers along the dipping part of the ocean bottom. This effect is caused by the destruction interference of the direct and the free surface reflected waves deflected by the ocean bottom topography.

A clear view of the overall wave propagation in the model including boundary-reflected $\mathrm{P}$ waves, and P-S and S-P converted waves at layers interfaces can be seen in snap shots of the vertical particle motion velocity on an E-W vertical plane crossing the source (Figure2 Right panel). Note that the geometry of the ocean bottom controls the amplitude of P-S and S-P converted waves as well as the propagation direction of $\mathrm{P}$ waves trapped within the water layer. The study of ocean-bottom topography and water layer effects on ground motion from a subduction zone earthquake will be the subject of the next phase of the project.

\section{References}

Pitarka, A. and K. Irikura (1996). Modeling 3D surface topography by finite-difference method: Kobe-JMA station site, Japan, case study, Geophys. Res. Lett. 23, 27292732.

Pitarka, A. (1999) 3D elastic finite-difference modelling of seismic motion using staggered-grid with non-uniform spacing. Bull. Seism. Soc. Am., 89,54-68.

Takenaka, T., T. Nakamura, T. Okamoto, and Y. Kaneda (2009). A unified approach implementing land and ocean-bottom topographies in the staggered-grid finitedifference method for seismic wave modeling, Proc. 9th SEGJ Int. Simp. 


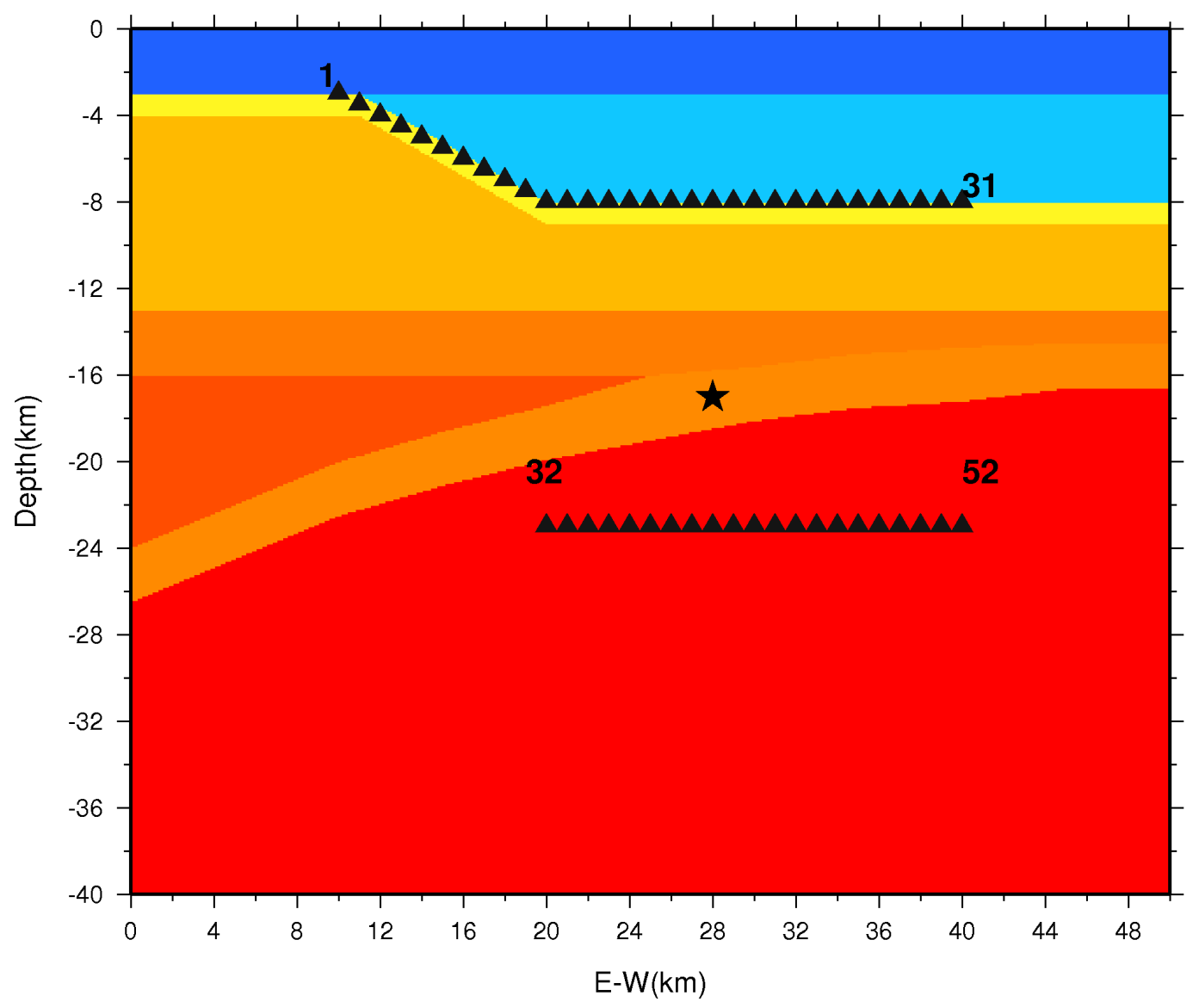

Figure1. E-W vertical cross-section of the velocity model. Star shows the point source location and triangles show stations location. 

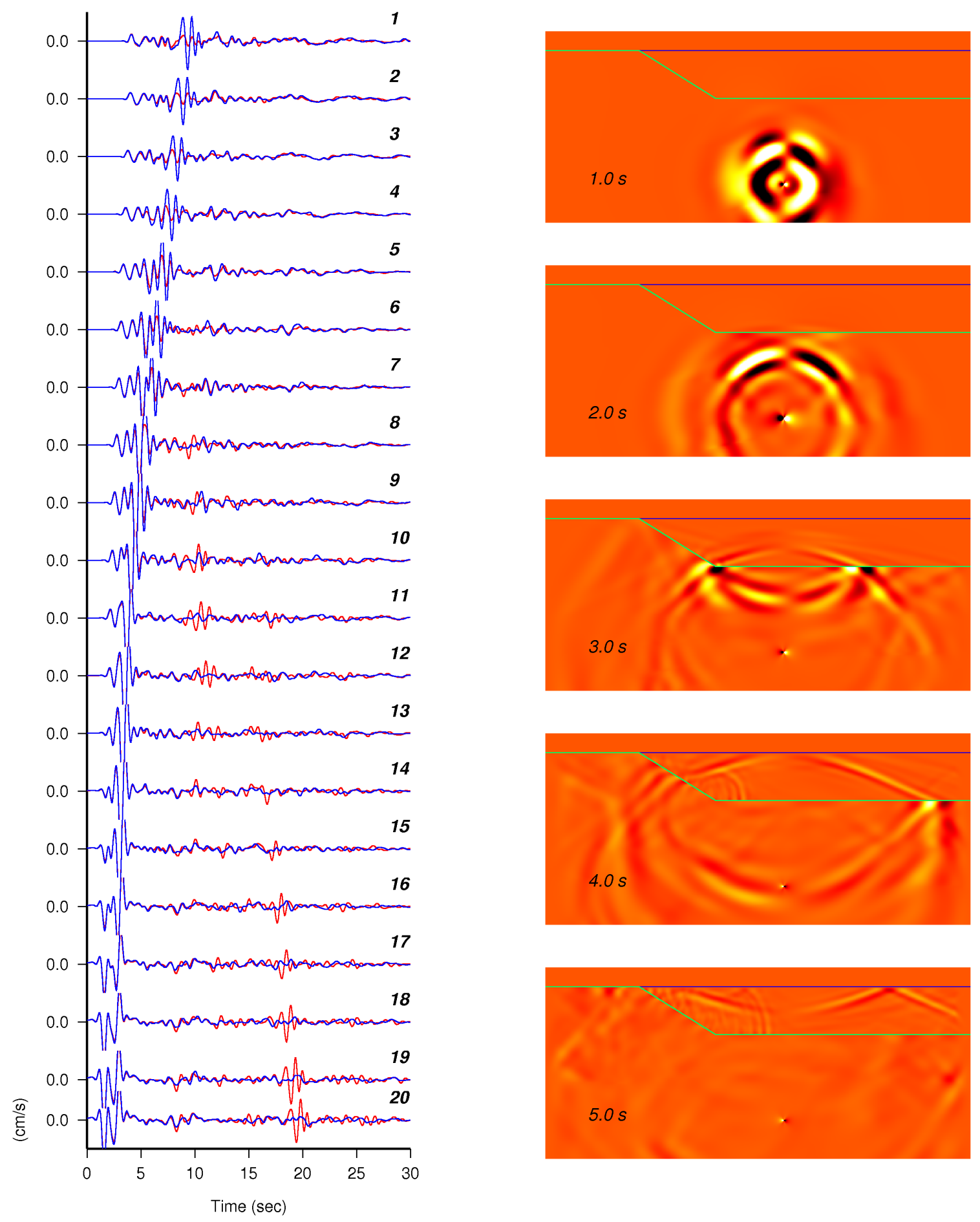

Figure 2. Left Panel: Vertical component of synthetic velocity seismograms calculated at rec\#1-22, band-pass filtered at 0.01-1.5 Hz. Blue traces are synthetics calculated for a model with water layer with infinite thickness (no liquid-air boundary). Red traces are calculated for a model with a liquid-air boundary.

Right Panel: Snapshots of the vertical component of velocity. Green line and blue line show the location of the solid-water and water-air boundaries, respectively 


\section{APPENDIX}

\section{A. List of Programs}

1. UL0_2.4W.F

2. GRIDXYZ.F

3. 3DMODL0 2.4 WATER.F

4. SURF MOD2.F

5. SNAPFILTER_SECTION.F

6. PROFIL.F

B. Sample Run Shell Scripts

1. RUN_EQ.CSH

2. SNAPFILTER.CSH

3. SNAP SUBD.GMT

4. PROFIL.CSH

5. PROFIL.GMT

C. Input Test Data Files

1. MODEL3 SUBD.DAT

2. POINT.DATT 